\title{
Effects of aging on the association between cerebrovascular responses to visual stimulation, hypercapnia and arterial stiffness
}

\section{Daniela Flück ${ }^{1,2+\neq}$, Andrew E. Beaudin ${ }^{2 \ddagger}$, Craig D. Steinback ${ }^{2}$, Gopukumar Kumarpillai $^{3}$, Nandavar Shobha ${ }^{3}$, Cheryl R. McCreary ${ }^{3,4,5,6}$, Stefano Peca ${ }^{6}$, Eric E. Smith ${ }^{3,4,6}$ and Marc J. Poulin ${ }^{2,3,4,7,8 *}$}

\footnotetext{
${ }^{1}$ Department of Biology, Institute of Human Movement Sciences and Sport, ETH Zurich, Zurich, Switzerland

${ }^{2}$ Department of Physiology and Pharmacology, Faculty of Medicine, University of Calgary, Calgary, AB, Canada

${ }^{3}$ Department of Clinical Neurosciences, Faculty of Medicine, University of Calgary, Calgary, AB, Canada

${ }^{4}$ Hotchkiss Brain Institute, Faculty of Medicine, University of Calgary, Calgary, AB, Canada

${ }^{5}$ Department of Radiology, Faculty of Medicine, University of Calgary, Calgary, AB, Canada

${ }^{6}$ Seaman Family MR Research Centre, Foothills Medical Centre, Alberta Health Services, Calgary, AB, Canada

7 Faculty of Kinesiology, University of Calgary, Calgary, AB, Canada

${ }^{8}$ The Libin Cardiovascular Institute of Alberta, Faculty of Medicine, University of Calgary, Calgary, AB, Canada
}

\section{Edited by:}

Patrice Brassard, Laval University,

Canada

\section{Reviewed by:}

Olaf Grisk, University of Greifswald, Germany

Christopher K Willie, University of

British Columbia Okanagan, Canada

\section{*Correspondence:}

Marc J. Poulin, Department of

Physiology and Pharmacology,

Faculty of Medicine, University of

Calgary, HMRB-210, 3330 Hospital

Drive NW, Calgary, Alberta,

T2N 4N1, Canada

e-mail:poulin@ucalgary.ca

${ }^{\dagger}$ Present address:

Daniela Flück, Zurich Center for

Integrative Human Physiology

(ZIHP), Institute of Physiology,

University of Zurich, Switzerland

F These authors have contributed equally to this work.
Aging is associated with decreased vascular compliance and diminished neurovascularand hypercapnia-evoked cerebral blood flow (CBF) responses. However, the interplay between arterial stiffness and reduced CBF responses is poorly understood. It was hypothesized that increased cerebral arterial stiffness is associated with reduced evoked responses to both, a flashing checkerboard visual stimulation (i.e., neurovascular coupling), and hypercapnia. To test this hypothesis, 20 older (64 \pm 8 year; mean $\pm S D$ ) and 10 young (30 \pm 5 year) subjects underwent a visual stimulation (VS) and a hypercapnic test. Blood velocity through the posterior (PCA) and middle cerebral (MCA) arteries was measured concurrently using transcranial Doppler ultrasound (TCD). Cerebral and systemic vascular stiffness were calculated from the cerebral blood velocity and systemic blood pressure waveforms, respectively. Cerebrovascular (MCA: young $=76 \pm 15 \%$, older $=98 \pm 19 \%, p=0.004 ;$ PCA: young $=80 \pm 16 \%$, older $=106 \pm 17 \%, p<0.001$ ) and systemic (young $=59 \pm 9 \%$ and older $=80 \pm 9 \%, p<0.001$ ) augmentation indices (AI) were higher in the older group. CBF responses to VS (PCA: $p<0.026$ ) and hypercapnia (PCA: $p=0.018$; MCA: $p=0.042$ ) were lower in the older group. A curvilinear model fitted to cerebral $\mathrm{Al}$ and age showed $\mathrm{Al}$ increases until 60 years of age, after which the increase levels off (PCA: $R^{2}=0.45, p<0.001$; MCA: $R^{2}=0.31, p<0.001$ ). Finally, MCA, but not PCA, hypercapnic reactivity was inversely related to cerebral Al (MCA: $R^{2}=0.28$, $p=0.002$; PCA: $\left.R^{2}=0.10, p=0.104\right)$. A similar inverse relationship was not observed with the PCA blood flow response to VS $\left(R^{2}=0.06, p=0.174\right)$. In conclusion, older subjects had reduced neurovascular- and hypercapnia-mediated CBF responses. Furthermore, lower hypercapnia-mediated blood flow responses through the MCA were associated with increased vascular stiffness. These findings suggest the reduced hypercapnia-evoked CBF responses through the MCA, in older individuals may be secondary to vascular stiffening.

Keywords: aging, cerebral blood flow, physiology, transcranial doppler, arterial stiffness

\section{INTRODUCTION}

Age manifests in systemic decreases in vascular compliance leading to an increased risk of stroke, cerebral white matter lesions, and cognitive decline (Mitchell et al., 2011; Laurent et al., 2012; Poels et al., 2012; Xu et al., 2012). In the brain, decreased resting cerebral blood flow $(\mathrm{CBF})$ and cerebrovascular reactivity to neuronal activation and alterations in arterial blood gases are also associated with an elevated risk of cerebrovascular disease (Jennings et al., 2013) and occur with healthy aging (Nishiyama et al., 1997; Fisher et al., 2013). Thus, the concurrent increase in cerebrovascular stiffness with aging may impact cerebrovascular responses (Fonck et al., 2009; Zhu et al., 2011) and thus contribute to the decreased CBF responses to neuronal stimulation and hypercapnia that occur with aging.

$\mathrm{CBF}$ is elevated in response to increased neural activity (i.e., neurovascular coupling) and hypercapnia. Neural activation leads to local increases in CBF via functional hyperemia, whereas hypercapnia produces a global increase in CBF, although there is heterogeneity between brain regions (Noth et al., 2008). With aging, resting CBF, neuronal-mediated increases in CBF, and CBF responses to hypercapnia have all been reported to decrease (Panczel et al., 1999; Niehaus et al., 2001; Fisher et al., 
2013; Jennings et al., 2013), but this is not a consistent finding with other studies reporting no change in neurovascular coupling (Rosengarten et al., 2003) or reactivity to hypercapnia (Schwertfeger et al., 2006; Galvin et al., 2010), and one study even reporting greater hypercapnia reactivity with healthy aging (Zhu et al., 2013). As such, the mechanisms regulating changes in resting $\mathrm{CBF}$ and $\mathrm{CBF}$ reactivity in response to neuronal activation and hypercapnia with aging are incompletely understood. Contributing mechanisms likely include brain atrophy, altered neuronal activity, and decreased cerebral metabolism (Leenders et al., 1990; Fisher et al., 2013), although endothelial and hemodynamic alterations may also contribute (Secher et al., 2008; Zhu et al., 2011; Fisher et al., 2013).

To assess neural-evoked increases in CBF, the approach of monitoring blood flow through the posterior cerebral artery (PCA) in response to a visual stimulus has been used extensively (Aaslid, 1987; Sturzenegger et al., 1996; Spelsberg et al., 1998; Panczel et al., 1999; Niehaus et al., 2001; Zaletel et al., 2004; Lisak et al., 2005; Smith et al., 2008; Rey et al., 2010), as the PCA supplies the majority of blood to the visual cortex (Edvinsson and Krause, 2002). Moreover, concurrent monitoring of middle cerebral artery (MCA) blood flow can be used as a negative control to confirm the locality of the visually-induced increase in blood flow through the PCA during such challenges since the MCA blood flow response to the same challenges is minimal (Aaslid, 1987; Smith et al., 2008).

The cerebral circulation is exquisitely sensitive to changes in the arterial partial pressure of carbon dioxide $\left(\mathrm{Pa}_{\mathrm{CO}_{2}}\right)$ (Berne et al., 1981; Poulin and Robbins, 1996), increasing with hypercapnia and decreasing with hypocapnia. In humans, blood velocity through both the PCA and MCA increase $~ 3-5 \%$ per $\mathrm{mmHg}$ increase in $\mathrm{PaCO}_{2}$ above resting values (Tominaga et al., 1976; Ide et al., 2003), and thus reflect the global influence of hypercapnia on CBF.

Transcranial Doppler ultrasound (TCD) is a useful noninvasive technique to assess both neural- and hypercapniamediated changes in $\mathrm{CBF}$ as well as cerebral hemodynamics on a beat-to-beat basis because of its high temporal resolution. Changes in CBF are typically monitored via changes in the peak velocity envelope averaged across a heartbeat while cerebral hemodynamics may be assessed by examining specific parameters of the peak blood velocity waveform (Robertson et al., 2008). In turn, these variables can provide measures of $\mathrm{CBF}$ reactivity to specific stimuli and cerebrovascular health, respectively.

Analogs to examining the pulse pressure waveform (Wilkinson et al., 1998), analysis of the TCD peak blood velocity waveform can be exploited to obtain a measure of arterial stiffening via calculation of a cerebral augmentation index (AI) (Kurji et al., 2006; Robertson et al., 2008). The AI is based on wave reflections throughout the vascular bed caused by vessel branching, changes in vessel wall diameter and/or material properties (Mitchell et al., 2011). The arrival of the reflected wave depends on the site of reflection as well as on the stiffness of the respective vessel being monitored. The stiffer the vessel, the higher the velocity of the forward and backward travelling waves, which leads to an earlier arrival of the reflected waves. The earlier arrival of the reflected wave is superimposed on the forward travelling wave and consequently higher velocity at the so-called reflective point of the peak blood velocity waveform (Laurent et al., 2006). Thus, an increase in AI is observed as vessels downstream of the monitored artery become less distensible with increasing age (Benetos et al., 1993).

Although mechanisms underlying neural- and hypercapniamediated vasodilation are unique to each stimulus, as both may be reduced with age, there is likely a common mechanism contributing to the decrease observed in each with increasing age. We speculate this common mechanism is age-related vascular mechanical dysfunction (i.e., reduced distensibility). As such, it was hypothesized that resting $\mathrm{CBF}$ and neural- and hypercapniaevoked increases in CBF would be attenuated with age, and attenuated neural- and hypercapnia-evoked CBF increases would be associated with elevated arterial stiffness (i.e., AI) within the PCA and MCA, respectively. To test this hypothesis, the relationship between $\mathrm{CBF}$ responses to a visual stimulus and a hypercapnic challenge with AI were examined and compared between young and older humans.

\section{METHODS \\ SUBJECTS}

Thirty subjects, 20 older ( 12 men; 8 women) and 10 younger ( 4 men, 6 females) participated in this study (Table 1). Exclusion criteria included age $<55$ y for the older group and age $<18$ or $>55 \mathrm{y}$ for the younger group, recent ( $<60$ days) change in blood pressure medication, uncontrolled hypertension, history of stroke, neurological disease, or dementia [defined according to the Diagnostic and Statistical Manual of Mental Disorders (American Psychiatric Association, 2000)]. A neurologist (Eric E. Smith) obtained clinical and medication histories, performed a neurological examination, and administered the Mini-Mental Status Examination (MMSE) cognitive test to all older volunteers (Folstein et al., 1975). Volunteers scoring $<23$ on the MMSE were excluded. Prior to experimental testing, subjects provided written and oral informed consent. The study was approved by the University of Calgary Conjoint Health Research Ethics Board.

\section{INSTRUMENTATION}

Bilateral TCD was used to measure PCA and MCA blood velocity simultaneously with subjects in a semi-supine position. The P2 segment of the PCA was monitored on the ipsilateral side of the dominant hand while the M2 segment of the MCA was monitored on the contralateral side. TCD probes were held in position by snug-fitting headgear (marc600, Spencer Technologies, Seattle, WA). Heart rate was measured using a 3-lead ECG (Micromon 7142B, Kontron Medical, Milton Keynes, UK); continuous arterial blood pressure was recorded non-invasively via finger photoplethysmography (Portapres, TPD Biomedical Instrumentation, Amsterdam, Netherlands) and intermittently from the brachial artery via an automated cuff (DINAMAP compact5, Critikon, New Jersey, USA); and arterial oxyhemoglobin saturation was collected via finger pulse oximetry (Datex-Ohmeda 3900, Helsinki, Finland). End-tidal partial pressures of oxygen $\left(\mathrm{PET}_{\mathrm{O}_{2}}\right)$ and carbon dioxide $\left(\mathrm{PET}_{\mathrm{CO}_{2}}\right)$ were monitored via a nasal cannula while 
Table 1 | Demographics of the study cohort and resting end-tidal partial pressures of $\mathrm{O}_{2}$ and $\mathrm{CO}_{2}$, and cerebral hemodynamic indices in the posterior and middle cerebral arteries.

\begin{tabular}{|c|c|c|c|}
\hline & Young & Older & $p$-values \\
\hline Age, years & $30 \pm 5$ & $64 \pm 8$ & $p<0.001$ \\
\hline Height, cm & $171 \pm 9$ & $169 \pm 0$ & $p=0.552$ \\
\hline Weight, kg & $67 \pm 13$ & $77 \pm 15$ & $p=0.084$ \\
\hline $\mathrm{SBP}, \mathrm{mmHg}$ & $112 \pm 9$ & $120 \pm 18$ & $p=0.188$ \\
\hline $\mathrm{DBP}, \mathrm{mmHg}$ & $66 \pm 6$ & $68 \pm 8$ & $p=0.571$ \\
\hline MAP, mmHg & $82 \pm 6$ & $85 \pm 10$ & $p=0.383$ \\
\hline Systemic Al, \% & $59.0 \pm 9.4$ & $80.3 \pm 9.0$ & $p<0.001$ \\
\hline $\mathrm{PET}_{2}$, Torr & $85.3 \pm 3.7$ & $88.6 \pm 6.4$ & $p=0.149$ \\
\hline PETCO, Torr & $35.2 \pm 3.3$ & $33.2 \pm 3.3$ & $p=0.133$ \\
\hline \multicolumn{4}{|c|}{ POSTERIOR CEREBRAL ARTERY } \\
\hline Sample size (n) & 10 & 18 & \\
\hline$V_{\text {dia }}, \mathrm{cm} / \mathrm{s}$ & $22.6 \pm 5.0$ & $21.3 \pm 5.0$ & $p=0.514$ \\
\hline$V_{\text {sys }}, \mathrm{cm} / \mathrm{s}$ & $53.3 \pm 12.0$ & $49.7 \pm 8.4$ & $p=0.354$ \\
\hline$V_{\text {mean }}, \mathrm{cm} / \mathrm{s}$ & $34.4 \pm 7.5$ & $33.7 \pm 7.2$ & $p=0.829$ \\
\hline$V_{\text {refl }}, \mathrm{cm} / \mathrm{s}$ & $46.3 \pm 9.4$ & $51.6 \pm 11.6$ & $p=0.224$ \\
\hline Cerebral Al, \% & $80.5 \pm 15.8$ & $106.8 \pm 16.8$ & $p<0.001$ \\
\hline $\mathrm{CVC}, \mathrm{cm} / \mathrm{s} / \mathrm{mmHg}$ & $0.43 \pm 0.11$ & $0.41 \pm 0.12$ & $p=0.694$ \\
\hline \multicolumn{4}{|c|}{ MIDDLE CEREBRAL ARTERY } \\
\hline Sample size (n) & 10 & 19 & \\
\hline$V_{\text {dia }}, \mathrm{cm} / \mathrm{s}$ & $40.0 \pm 5.2$ & $28.4 \pm 7.4$ & $p<0.001$ \\
\hline$V_{\text {sys }}, \mathrm{cm} / \mathrm{s}$ & $94.2 \pm 18.2$ & $68.1 \pm 11.8$ & $p<0.001$ \\
\hline$V_{\text {mean }}, \mathrm{cm} / \mathrm{s}$ & $60.0 \pm 8.8$ & $44.5 \pm 9.3$ & $p<0.001$ \\
\hline$V_{\text {refl }}, \mathrm{cm} / \mathrm{s}$ & $79.8 \pm 13.7$ & $66.8 \pm 14.0$ & $p=0.024$ \\
\hline Cerebral Al, \% & $76.1 \pm 15.5$ & $98.0 \pm 19.0$ & $p=0.004$ \\
\hline $\mathrm{CVC}, \mathrm{cm} / \mathrm{s} / \mathrm{mmHg}$ & $0.74 \pm 0.15$ & $0.54 \pm 0.13$ & $p<0.001$ \\
\hline
\end{tabular}

Values are means $\pm S D$.

SBP, systolic blood pressure; DBP, diastolic blood pressure; MAP, mean arterial blood pressure; systemic Al, systemic augmentation index; $\mathrm{PET}_{\mathrm{CO}}$, end-tidal partial pressure of $\mathrm{CO}_{2} ; P \mathrm{ET} \mathrm{O}_{2}$, end-tidal partial pressure of $\mathrm{O}_{2} ; V_{\text {dia, velocity }}$ at diastole; $V_{\text {sys }}$, velocity at systole; $V_{\text {mean, }}$ average velocity over cardiac cycle;

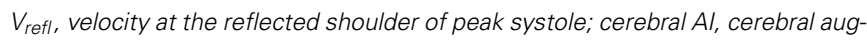
mentation index; $C V C$, cerebrovascular conductance; p-values: older compared to young. The bold p-values are to highlight the significant differences that were observed.

subjects performed a visual stimulation test. Next, a euoxic hypercapnic test was administered using the technique of dynamic end-tidal forcing (DEF) with the subject breathing through a mouthpiece with their nose occluded (Ide et al., 2003). The DEF system uses a negative feedback loop to control $\mathrm{PET}_{\mathrm{CO}_{2}}$ and $\mathrm{PET}_{\mathrm{O}_{2}}$ at desired levels by adjusting the inspired fraction of $\mathrm{CO}_{2}$ $\left(\mathrm{F}_{\mathrm{I}} \mathrm{CO}_{2}\right)$ and $\mathrm{O}_{2}\left(\mathrm{~F}_{\mathrm{I}} \mathrm{O}_{2}\right)$ on a breath-by-breath basis using custom designed, dedicated software (BreatheM, v2.38, University Laboratory of Physiology, Oxford, UK) (Vantanajal et al., 2007; Beaudin et al., 2011). The DEF system controls $\mathrm{PET}_{\mathrm{CO}_{2}}$ and $\mathrm{PET}_{\mathrm{O}_{2}}$ at desired levels independent of ventilatory frequency and depth. Respired gases were sampled at $20 \mathrm{~mL} / \mathrm{min}$ via a fine capillary inserted into the nasal cannula during the visual stimulation test or the mouthpiece during the euoxic hypercapnic test for continuous analysis of $\mathrm{F}_{\mathrm{I}} \mathrm{CO}_{2}$ and $\mathrm{F}_{\mathrm{I}} \mathrm{O}_{2}$ by mass spectrometry (AMIS 2000, Innovision, Odense, Denmark).

\section{VISUAL STIMULATION}

To assess the CBF response to visual stimulation, the subject sat $\sim 50 \mathrm{~cm}$ from a $38.1 \mathrm{~cm}$ (i.e., $15 \mathrm{in}$ ) computer screen with their eyes in line with its center when looking straight ahead (Smith et al., 2008). Following instrumentation, the test started with a 2 min baseline consisting of looking at a black cross (height and width $\sim 1.5 \mathrm{~cm}$ ) centered on a dark gray background. Baseline was followed by either 10 cycles of 40 s blocks $(n=9$ older subjects) or 5 cycles of $80 \mathrm{~s}$ blocks $(n=11$ older subjects and all young subjects) involving the flashing of an alternating black and white checkerboard stimulus for 20 or $40 \mathrm{~s}(\mathrm{ON})$, respectively. The ON stage was followed by 20 or 40 s of rest (OFF) where the screens display was the same as baseline conditions. The subject was instructed to always focus their eyes on the computer screen and their thoughts on the present task, and was monitored continuously to verify they were attending to the stimulus. All tests were performed in a darkened room.

This visual stimulation paradigm was chosen to minimize participant burden as it was also used with elderly stroke patients (data not reported), some of whom had mild dementia (Peca et al., 2013) and difficulty following relatively simple tasks. Therefore, using the current visual stimulation paradigm simplified the task by removing the necessity of continuously instructing subjects when to open and close their eyes.

\section{EUOXIC HYPERCAPNIC TEST}

The euoxic hypercapnic test began with $10 \mathrm{~min}$ of air breathing to determine mean resting $\mathrm{PET}_{\mathrm{CO}_{2}}$ and $\mathrm{PET}_{\mathrm{O}_{2}}$ values. These mean resting end-tidal values were used to create an individualized hypercapnic protocol (Ide et al., 2003). The euoxic hypercapnic test consisted of three 120 s steps: Baseline $\left(\mathrm{PET}_{\mathrm{CO}_{2}}=+1.5\right.$ Torr above resting values), Hypercapnia $\left(\mathrm{PET}_{\mathrm{CO}_{2}}=+6.5\right.$ Torr above resting values $)$, and Recovery $\left(\mathrm{PET}_{\mathrm{CO}_{2}}=+1.5\right.$ Torr above resting values). Throughout the entire hypercapnic test, $\mathrm{PET}_{\mathrm{O}_{2}}$ was maintained at 88 Torr (mean euoxic $\mathrm{PET}_{\mathrm{O}_{2}}$ for the altitude $(1103 \mathrm{~m}$ above sea level) at which the laboratory is located). Maintaining $\mathrm{PET}_{\mathrm{CO}_{2}}$ at +1.5 Torr above air breathing resting values during the Baseline and Recovery facilitates $\mathrm{PET}_{\mathrm{CO}_{2}}$ control (Ide et al., 2003) and reduces breath-to-breath variability in CBF velocity (Harris et al., 2006).

\section{ANALYSIS}

The peak velocity associated with the maximal Doppler frequency shift was averaged over each heart beat $\left(V_{\text {mean }} ; \mathrm{cm} / \mathrm{s}\right)$ and utilized as an index of CBF through the PCA and MCA.

Velocity waveform analysis was performed using a custom written Matlab program (Robertson et al., 2008). Output parameters included the diastolic minimum velocity $\left(V_{\text {dia }}\right)$, velocity at systole $\left(V_{\text {sys }}\right)$, velocity at the reflective shoulder $\left(V_{\text {refl }}\right)$, and mean peak velocity $\left(V_{\text {mean }}\right)$ (Figure 1$)$. Next, the cerebral augmentation index (AI) was calculated (Kurji et al., 2006; Robertson et al., 2008):

$$
\text { Cerebral AI }=\frac{V_{\text {refl }}-V_{\text {dia }}}{V_{\text {sys }}-V_{\text {dia }}} \times 100
$$

Finally, utilizing mean arterial pressure (MAP), beat-to-beat PCA and MCA cerebrovascular conductance (CVC) was calculated as: 


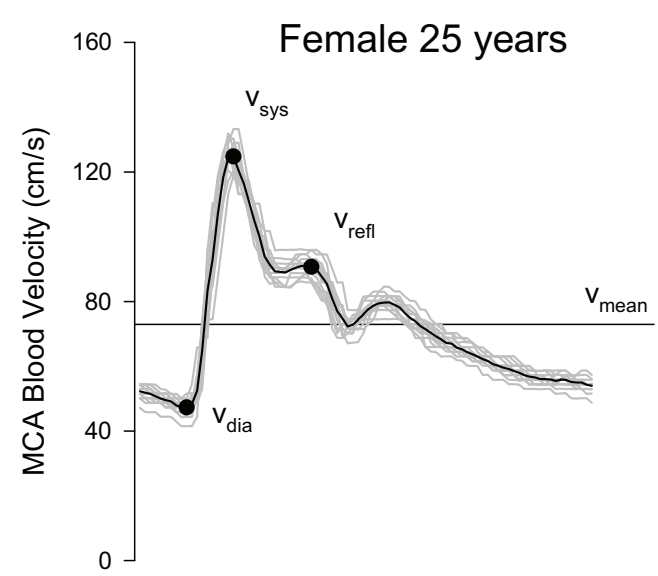

\section{Female 66 years}
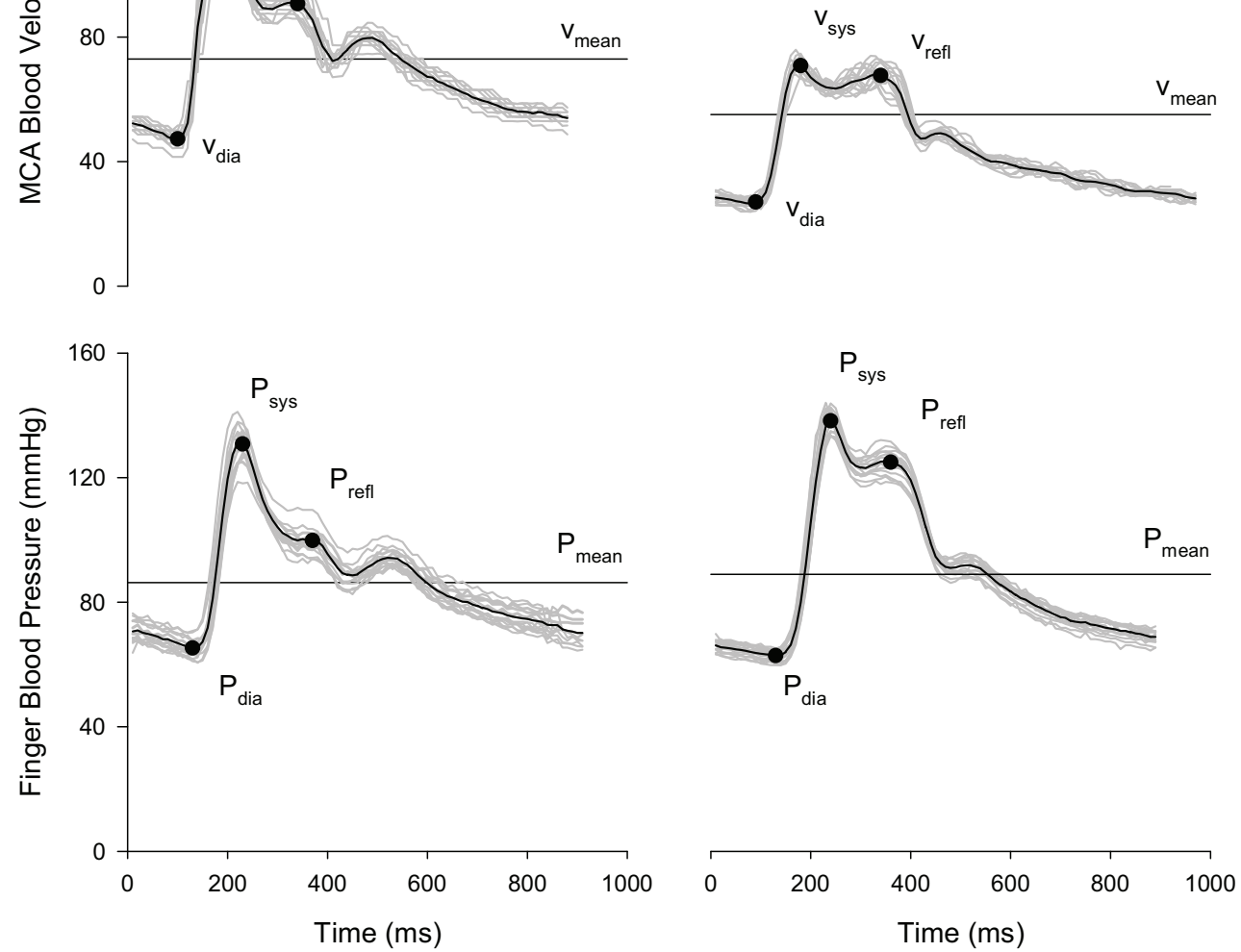

FIGURE 1 | Representative MCA blood velocity and finger blood pressure waveforms of a young (age $=25$ years) and older (age $=66$ years) volunteer at rest. Each plot shows the overlay

$$
\mathrm{CVC}=\frac{V_{\text {mean }}}{\mathrm{MAP}}
$$

Visual waveform analysis was performed using the final $60 \mathrm{~s}$ of baseline and the final $30 \mathrm{~s}$ of a minimum of three $\mathrm{ON}$ phases ( $15 \mathrm{~s}$ for $40 \mathrm{~s}$ blocks). For the hypercapnic test, the final $60 \mathrm{~s}$ of the baseline and hypercapnic stage were analyzed to determine hypercapnic responses. Absolute blood flow changes in response to visual stimulation and hypercapnia were calculated by subtracting the baseline values from the $\mathrm{ON}$ phase and hypercapnia values, respectively. In addition, the relative (i.e., percent) change in blood flow from the preceding baseline in response to the visual stimulation and hypercapnia were calculated. Subsequently, PCA and MCA reactivity to hypercapnia was quantified in absolute $(\mathrm{cm} / \mathrm{s} /$ Torr $)$ and relative (\%/Torr) units by dividing the respective increases in PCA and MCA blood velocity by the change in $\mathrm{PET}_{\mathrm{CO}_{2}}$ from baseline into hypercapnia.

Systemic pressure waveform parameters were analyzed using the same automated algorithms implemented in Matlab used to of individual cardiac cycles (gray lines) over 15s, the composite (i.e., mean waveform; black line), and the location of the waveform parameters.

analyze the velocity waveforms. Systemic AI was calculated analogically to the cerebral AI using systolic blood pressure $\left(P_{\text {sys }}\right)$, diastolic blood pressure $\left(P_{\text {dia }}\right)$ and blood pressure at the reflective shoulder $\left(P_{\text {refl }}\right)$.

$$
\text { Systemic AI }=\frac{P_{\text {refl }}-P_{\text {dia }}}{P_{\text {sys }}-P_{\text {dia }}} \times 100
$$

\section{STATISTICAL ANALYSIS}

All measured parameters had a normal distribution as assessed by the Kolmogorov-Smirnov Test. Differences in subject demographics and resting cerebrovascular hemodynamic parameters were compared using independent Student $T$-Tests. Next, within- and between-subject differences in responses to the visual stimulation and euoxic hypercapnia tests were assessed using 2by-2 mixed factor repeated measures analyses of variance (RM ANOVA). The within-subject factor for the visual stimulation test was Visual Stimulation Stages (OFF and ON) and the withinsubject factor for the hypercapnic test was Hypercapnic Test 
Stages (Baseline and Hypercapnia). The between-subject factor was Age Groups (Young and Older). If there was a significant main effect of Visual Stimulation Stages or Hypercapnic Stages, post-hoc within-subject differences in cerebral blood velocity and waveform parameters between the OFF and ON or the Baseline and Hypercapnic stages (irrespective of Age Groups) were compared using paired Student $T$-Tests. If the interaction between the Visual Stimulation Stages or Hypercapnic Test Stages and Age Groups was significant [or showed a trend to be significant (i.e., $0.05 \leq p \leq 0.100$ )], the magnitude of the response (i.e., absolute and relative delta values) for each age group were compared using independent 1-tailed Student T-Tests. All post-hoc analyses incorporated a Bonferroni correction for multiple comparisons.

Based upon previously published reports showing a curvilinear relationship between systemic AI and age (Kelly et al., 1989; Mitchell et al., 2004; McEniery et al., 2005), a similar relationship was plotted between cerebral AI and age. Alpha was set $a$ priori at $p \leq 0.05$. Finally, the Pearson product-moment correlation was used to examine relationships between cerebral and systemic AI, changes in PCA blood velocity in response to the visual stimulation and cerebral AI, and hypercapnic reactivity for the PCA and MCA and cerebral AI. Statistical analyses were performed using SAS Enterprise Guide (4.3, SAS Institute Inc., Cary, NC, USA).

\section{RESULTS}

All study subjects $(n=30)$ completed the study. The TCD signal was of insufficient quality for analysis of PCA blood velocity in two older volunteers and of MCA blood velocity in one older volunteer. Subject demographics, resting blood pressure, resting $\mathrm{PET}_{\mathrm{O}_{2}}$ and $\mathrm{PET}_{\mathrm{CO}_{2}}$, and cerebral blood velocity parameters are presented in Table 1. Briefly, the young and older subjects were of similar height $(p=0.552)$ and weight $(p=0.084)$ and had similar systolic (SBP), diastolic (DBP) and mean arterial (MAP) blood pressures $\left(p \geq 0.188\right.$ ). Additionally, resting, air breathing $\mathrm{PET}_{\mathrm{O}_{2}}$ and $\mathrm{PET}_{\mathrm{CO}_{2}}$ were similar between the two age groups $(p \geq 0.133)$. In contrast, the older group had a significantly higher systemic AI $(p<0.001)$.

\section{RESTING CEREBROVASCULAR HEMODYNAMIC PARAMETERS}

At rest, while the subjects were breathing room air, PCA diastolic $\left(V_{\text {dia }}\right)$, systolic $\left(V_{\text {sys }}\right)$, mean $\left(V_{\text {mean }}\right)$, and reflected $\left(V_{\text {refl }}\right)$ blood velocities, as well as CVC, were similar between the young and older subjects ( $p \geq 0.224)$. Oppositely, PCA cerebral AI was lower in the young group $(p<0.001)$. For the MCA, all blood velocity waveform parameters (i.e., $V_{\text {dia }}, V_{\text {sys }}, V_{\text {mean }}$, and $\left.V_{\text {refl }}\right)$ and CVC were higher $(p \leq 0.024)$, and cerebral AI was lower in the young group $(p=0.004)$.

\section{RESPONSES TO VISUAL STIMULATION}

There was no effect of the Visual Stimulation Stages and the interaction between the Visual Stimulation Stages and Age Groups main effects were not significant for $\operatorname{PET}_{\mathrm{O}_{2}}(p \geq 0.347)$, $\operatorname{PET}_{\mathrm{CO}_{2}}(p \geq 0.518)$, or MAP $(p \geq 0.107)$. Thus, there was no change in $\mathrm{PET}_{\mathrm{O}_{2}}, \mathrm{PET}_{\mathrm{CO}_{2}}$, and MAP in response to the visual stimulation, irrespective of age, and any changes in $\mathrm{PET}_{\mathrm{O}_{2}}$, $\mathrm{PET}_{\mathrm{CO}_{2}}$, and MAP that occurred within each age group were similar (Table 2).
In the older group, visually evoked increases in PCA blood velocity were similar between those who performed 10 cycles of $40 \mathrm{~s}$ blocks and those who performed 5 cycles of $80 \mathrm{~s}$ blocks $(p=0.172)$. Thus, responses were grouped to provide a single group mean. The mean change in absolute, and relative, visually evoked changes in PCA and MCA mean blood velocities ( $\left.V_{\text {mean }}\right)$ and CVC for both the young and older groups are shown in Figure 2. The Visual Stimulation Stages main effect was significant for both PCA $(p<0.001)$, and MCA, $V_{\text {mean }}(p=0.041)$ with $V_{\text {mean }}$, being higher during the $\mathrm{ON}$ stage for both arteries $(p \leq 0.041)$ regardless of age. The increase in PCA $V_{\text {mean }}$ was $3.4 \pm 2.5 \mathrm{~cm} / \mathrm{s}(10.3 \pm 7.6 \%)$, which was greater $(p \leq 0.001)$ than the increase in MCA $V_{\text {mean }}$ of $1.1 \pm 2.4 \mathrm{~cm} / \mathrm{s}(2.6 \pm 5.7 \%)$. Moreover, the interaction between the Visual Stimulation Stages and Age Groups main effects was significant for PCA $V_{\text {mean }}(p=$ $0.037)$ as a result of a greater increase in absolute (and relative) PCA $V_{\text {mean }}$ in the young group ( $p \leq 0.026$; Figure $2 \mathrm{~A}$ ). The nonsignificant interaction between Visual Stimulation Stages and Age Groups for the MCA $V_{\text {mean }}$ signifies the increase in MCA $V_{\text {mean }}$ was similar between the two age groups (Figure 2A).

There was a significant effect of the Visual Stimulation Stages on PCA CVC $(p \leq 0.001)$, but not MCA CVC $(p=0.381)$. Regardless of age, PCA CVC was higher during the ON stage of the visual stimulation test $(p \leq 0.001)$. In addition, there was a trend for the interaction between the Visual Stimulation Stages and Age Groups main effects to be significant for PCA CVC ( $p=$ $0.067)$ while the interaction was not significant for MCA CVC $(p=0.187$; Figure 2B). Although the interaction term showed only a trend, post-hoc 1-tailed comparisons of the change in PCA CVC (absolute and relative) showed the increase in CVC was greater in the young group ( $p \leq 0.034$; Figure $2 \mathrm{~B}$ ).

Finally, the Visual Stimulation Stages main effect was significant for PCA $V_{\text {dia }}, V_{\text {sys }}$, and $V_{\text {refl }}(p \leq 0.001)$ as all velocities were elevated in response to the visual stimuli within the young and older groups. In contrast, the Visual Stimulation Stages main effect was significant for only MCA $V_{\text {dia }}(p=0.015)$ with it being elevated in response to the visual stimuli (Table 2). Additionally, there was a significant interaction between the Visual Stimulation Stages and Age Groups main effects for PCA $V_{\text {dia }}(p=0.032)$ and $V_{\text {sys }}(p=0.028)$ with the young subjects having a greater increase in the two velocities in response to the visual stimuli (Table 2). The interaction was not significant for MCA $V_{\text {dia }}, V_{\text {sys }}$, and $V_{\text {refl }}$ $(p \geq 0.187)$.

\section{RESPONSES TO EUOXIC HYPERCAPNIA}

Baseline $\mathrm{PET}_{\mathrm{O}_{2}}$ and $\mathrm{PET}_{\mathrm{CO}_{2}}$ were $87.8 \pm 2.4$ Torr and $37.3 \pm 3.0$ Torr for the young group and $87.8 \pm 1.8$ Torr and $35.6 \pm 3.3$ Torr in the older group $(p \geq 0.172)$. Subsequently, $\mathrm{PET}_{\mathrm{O}_{2}}$ and $\mathrm{PET}_{\mathrm{CO}_{2}}$ during the hypercapnic stage were $87.5 \pm 2.0$ Torr and $41.8 \pm$ 3.2 Torr in the young group and $87.3 \pm 1.8$ Torr and $40.5 \pm$ 3.0 Torr in the older group ( $p \geq 0.277)$. There was no interaction between the Hypercapnic Stages and Age Groups for either $\mathrm{PET}_{\mathrm{O}_{2}}$ or $\mathrm{PET}_{\mathrm{CO}_{2}}(p \geq 0.326)$. Thus, $\mathrm{PET}_{\mathrm{O}_{2}}$ and the increase in $\mathrm{PET}_{\mathrm{CO}_{2}}$, with hypercapnia were similar between young and older subjects ( $p \geq 0.728$; Table 2 ). For MAP, there was a significant effect the Hypercapnic Stages $(p<0.001)$ as MAP was increased with hypercapnia irrespective of age. The interaction between the 
Table 2 | Changes in $\mathrm{PET}_{\mathrm{CO}_{2}}, \mathrm{PET}_{\mathrm{O}_{2}}$, MAP, and absolute and relative (i.e., percent) changes in cerebral waveform parameters for the posterior and middle cerebral arteries in response to the visual stimulation and $\mathrm{CO}_{2}$ test in the young and older groups.

\begin{tabular}{|c|c|c|c|c|c|c|}
\hline & \multicolumn{3}{|c|}{ Visual stimulation } & \multicolumn{3}{|c|}{$\mathrm{CO}_{2}$ Test } \\
\hline$\Delta \mathrm{PET}_{2}$ (Torr) & $-1.0 \pm 2.7$ & $-0.3 \pm 3.5$ & $p=0.585$ & $-0.4 \pm 2.4$ & $-0.4 \pm 2.4$ & $p=0.970$ \\
\hline$\triangle \mathrm{MAP}$ & $-2.2 \pm 2.8$ & $1.42 \pm 6.5$ & $p=0.107$ & $4.3 \pm 4.2$ & $3.6 \pm 4.9$ & $p=0.712$ \\
\hline \multicolumn{7}{|c|}{ POSTERIOR CEREBRAL ARTERY } \\
\hline$\Delta V_{\text {dia }}, \%$ & $16.6 \pm 7.7$ & $11.3 \pm 8.8$ & $p=0.059$ & $24.0 \pm 7.5$ & $15.7 \pm 8.6$ & $p=0.009$ \\
\hline$\Delta V_{\text {sys }}, \mathrm{cm} / \mathrm{s}$ & $5.3 \pm 3.6$ & $2.7 \pm 2.5$ & $p=0.014$ & $7.5 \pm 4.6$ & $4.7 \pm 3.2$ & $p=0.035$ \\
\hline$\Delta V_{\text {sys }}, \%$ & $10.5 \pm 7.1$ & $5.6 \pm 4.9$ & $p=0.019$ & $13.7 \pm 7.5$ & $10.1 \pm 6.2$ & $p=0.088$ \\
\hline$\Delta V_{\text {refl, }}, \mathrm{cm} / \mathrm{s}$ & $5.7 \pm 3.1$ & $3.6 \pm 3.2$ & $p=0.047$ & $9.0 \pm 3.3$ & $5.9 \pm 3.3$ & $p=0.012$ \\
\hline$\Delta V_{\text {refl }}, \%$ & $12.8 \pm 7.0$ & $7.2 \pm 6.6$ & $p=0.022$ & $17.1 \pm 7.1$ & $11.9 \pm 7.3$ & $p=0.041$ \\
\hline$\Delta V_{\text {dia }}, \%$ & $1.7 \pm 5.2$ & $5.8 \pm 9.6$ & $p=0.110$ & $23.6 \pm 6.4$ & $18.2 \pm 6.8$ & $p=0.024$ \\
\hline$\Delta V_{\text {sys }}, \mathrm{cm} / \mathrm{s}$ & $-0.3 \pm 4.4$ & $1.4 \pm 2.3$ & $p=0.093$ & $11.6 \pm 5.2$ & $7.9 \pm 5.0$ & $p=0.034$ \\
\hline$\Delta V_{\text {sys }}, \%$ & $-0.2 \pm 4.7$ & $2.2 \pm 3.4$ & $p=0.061$ & $12.0 \pm 4.5$ & $11.7 \pm 7.4$ & $p=0.465$ \\
\hline$\Delta V_{\text {refl, }}, \mathrm{cm} / \mathrm{s}$ & $0.9 \pm 3.7$ & $1.6 \pm 3.5$ & $p=0.299$ & $15.7 \pm 3.8$ & $10.3 \pm 4.8$ & $p=0.002$ \\
\hline$\Delta V_{\text {refl }}, \%$ & $1.2 \pm 4.9$ & $2.7 \pm 6.3$ & $p=0.263$ & $17.7 \pm 3.9$ & $14.9 \pm 7.5$ & $p=0.150$ \\
\hline
\end{tabular}

Values are means $\pm S D$.

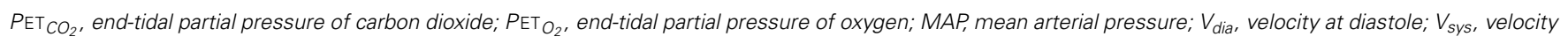
at systole; $V_{\text {refl, }}$ velocity at the reflected shoulder of peak systole; cerebral Al, cerebral augmentation index; CVC, cerebrovascular conductance.

$P$-values within table are for older vs. young comparisons. The bold p-values are to highlight the significant differences that were observed.

Hypercapnic Stages and Age Groups main effects was not significant $(p=0.712)$ as the increase in MAP was similar between young and older subjects (Table 2).

Absolute and relative increases in PCA and MCA $V_{\text {mean }}$, and CVC with hypercapnia are shown in Figure 3. There was a significant interaction between the Hypercapnic Stages and Age Groups main effects for both PCA $(p=0.004)$ and MCA $(p<0.001) V_{\text {mean }}$. In addition, the interaction between the Hypercapnic Stages and Age Groups was significant for CVC in both arteries (PCA: $p=0.039$; MCA: $p=0.007$ ). Post-hoc comparisons showed the absolute, and relative, increases in PCA $V_{\text {mean }}$ were significantly lower in older subjects $(p \leq 0.031)$ while the absolute increase in MCA $V_{\text {mean }}$ was lower in the older subjects $(p \leq 0.001)$ and the relative increase in MCA $V_{\text {mean }}$ showed a trend to be lower in the older group $(p=0.097)$. Also, the absolute increase in CVC with hypercapnia was lower in the older group for both the PCA $(p=0.025)$, and MCA $(p=0.005)$, but the relative increase in CVC showed only a trend to be lower in the older group for the PCA $(p=0.057)$ while MCA CVC was similar between the two groups $(p=$ 0.237). The interaction between the Hypercapnic Stages and Age Groups main effects was significant for PCA and MCA $V_{\text {dia }}(p \leq 0.001)$ and $V_{\text {refl }}(p \leq 0.024)$, but not $V_{\text {sys }}(p \geq 0.068)$. Table 2 shows the results of post-hoc age group comparisons of the change in PCA and MCA $V_{\text {dia }}, V_{\text {sys }}$, and $V_{\text {refl }}$ with hypercapnia.
The smaller absolute, and relative, increases in PCA $V_{\text {mean }}$ within the older group translated into lower absolute (i.e., $\mathrm{cm} / \mathrm{s} /$ Torr) and relative (i.e., \%/Torr) reactivities to hypercapnia ( $p \leq 0.018)$ compared to the young group (Figure 4). Similarly, absolute, and relative, MCA hypercapnia reactivity was lower in the older group $(p \leq 0.042)$. Relative PCA and MCA hypercapnic reactivity values for the older group have been previously reported in comparison to a patient population (Peca et al., 2013).

\section{VISUALLY-EVOKED AND HYPERCAPNIC CBF RESPONSES: RELATION TO ARTERIAL STIFFNESS}

Cerebral AI for both the PCA and the MCA was highly correlated ( $p<0.001$ ) with systemic AI (Figure 5A). Furthermore, the curvilinear model fitted to the cerebral AI and age relationship was significant for both arteries ( $p<0.001$; Figure 5B). Figure 6 shows the relationships between responses in PCA $V_{\text {mean }}$ to the visual stimulation and cerebral $\mathrm{AI}$ as well as the relationships between PCA and MCA hypercapnia reactivities and cerebral AI. The change in PCA $V_{\text {mean }}$ (relative and absolute) in response to the visual stimulation was not related cerebral AI ( $p \geq 0.128)$. Similarly, the correlations between absolute, and relative, PCA hypercapnia reactivity and cerebral AI were not significant $(p \geq$ 103). In contrast, there was a significant negative correlation between relative, and absolute, measures of MCA hypercapnia reactivities and cerebral AI $(p \leq 0.013)$ with lower reactivity at higher cerebral AIs. 


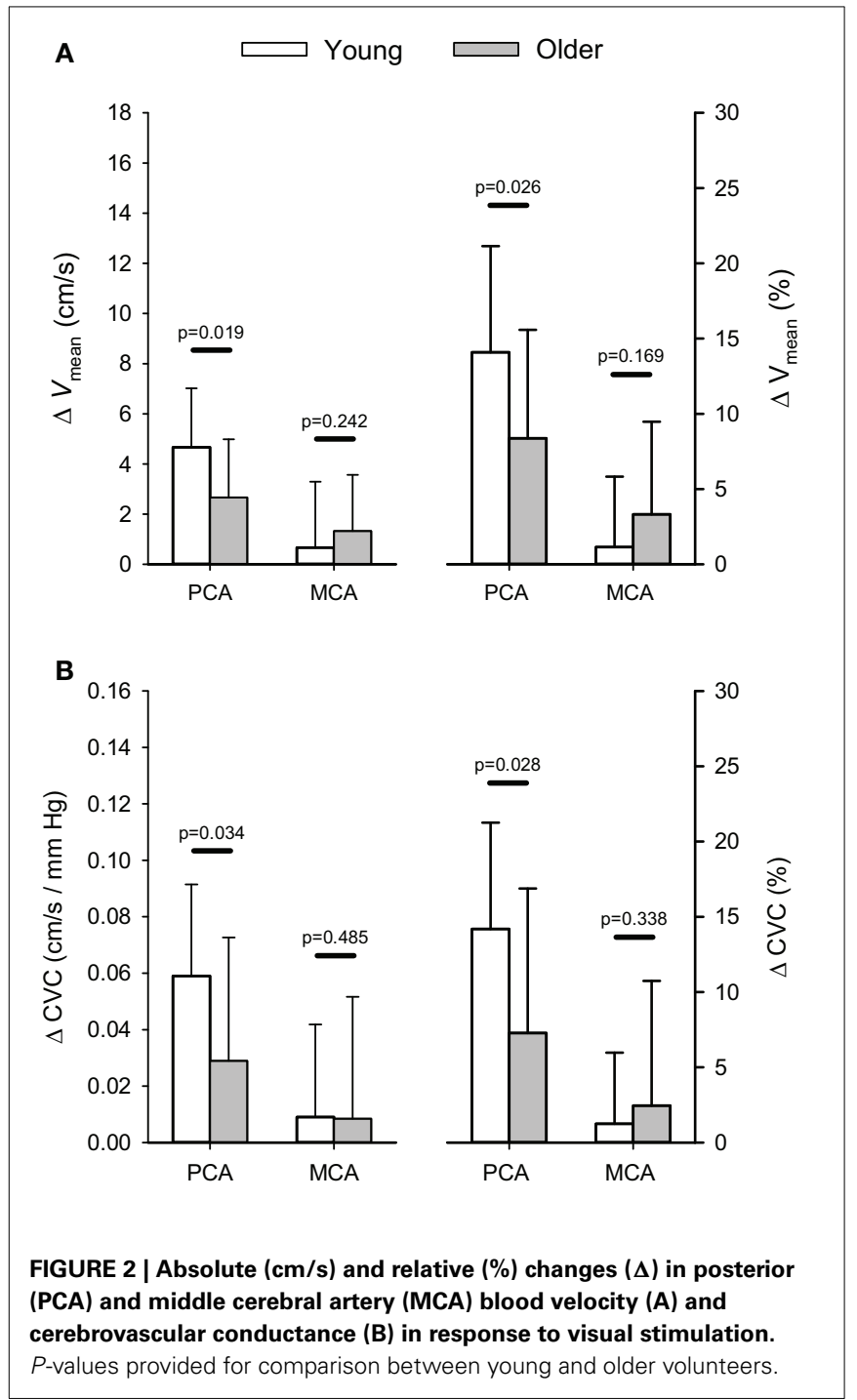

\section{DISCUSSION}

In this study we assessed age-related changes in resting $\mathrm{CBF}$ through two cerebral arteries (PCA and MCA), as well as changes in CBF through the PCA and MCA in response to neuronal activation (via a visual stimulus) and hypercapnia in young and older healthy humans. The main findings were (1) resting PCA blood flow was not reduced with age, but resting MCA blood flow was lower in older subjects, (2) CBF responses to visual stimulation and hypercapnia were lower in older subjects; (3) cerebral and systemic AI increased with age and were highly correlated; and (4) cerebrovascular reactivity to hypercapnia through the MCA was inversely related to cerebral AI.

Resting CBF has been reported to decrease with advancing age (Kety, 1956; Leenders et al., 1990), but this is not a consistent finding (Yamaguchi et al., 1986). Reduced cerebral metabolism and brain atrophy are likely primary contributors to the age-related reduction in CBF (Leenders et al., 1990), but hemodynamic alterations such as increased arterial stiffness may also be involved (Zhu et al., 2011). In the current study, resting PCA blood flow
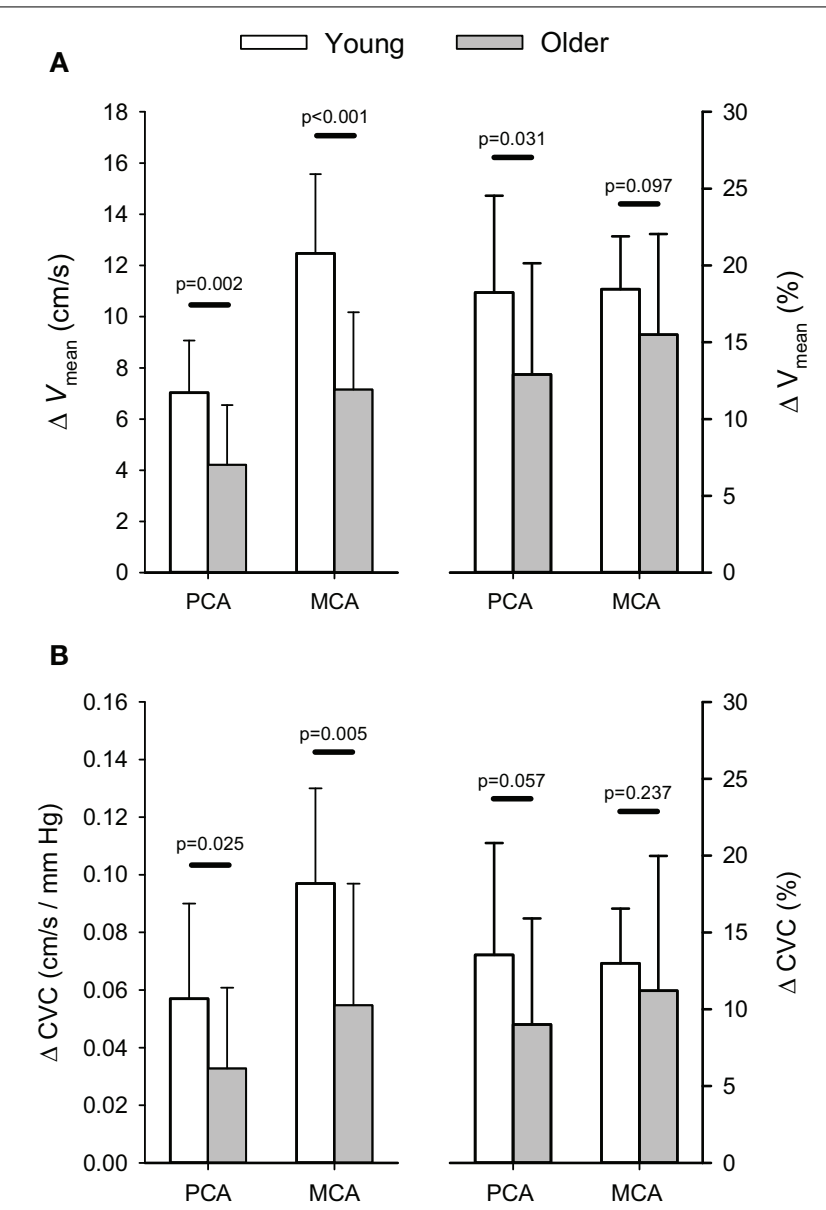

FIGURE 3 | Absolute $(\mathrm{cm} / \mathrm{s})$ and relative $(\%)$ changes $(\Delta)$ in posterior (PCA) and middle cerebral artery (MCA) blood velocity (A) and cerebrovascular conductance $(B)$ in response to euoxic hypercapnic test. $P$-values provided for comparison between young and older volunteers

was similar between the young and older groups, while the MCA blood flow was significantly lower in the older group. The lower resting MCA blood flow is consistent with prior studies utilizing TCD (Nishiyama et al., 1997; Ainslie et al., 2008; Secher et al., 2008; Galvin et al., 2010; Zhu et al., 2013), but the maintained resting PCA blood flow in the older group is in contrast to two previous studies that reported concurrent decreases in both PCA, and MCA, blood flow with aging (Muller and Schimrigk, 1994; Demirkaya et al., 2008). However, in the study by Muller and Schimrigk (1994) the age-related decline was more pronounced for the MCA than the PCA-29 vs. $17 \%$. Oppositely, Demirkaya et al. (2008) reported a $\sim 20 \%$ decrease in both MCA and PCA blood flow with increasing age. In conjunction with the findings by Muller and Schimrigk (1994), the observation of a maintained resting PCA blood flow, but a lower resting MCA blood flow, reflect potential regional differences in cerebrovascular changes with aging. These contrasting changes in PCA and MCA blood flow may be the result of the PCA being a smaller artery with, generally, lower blood flow compared to the MCA. As a result, 


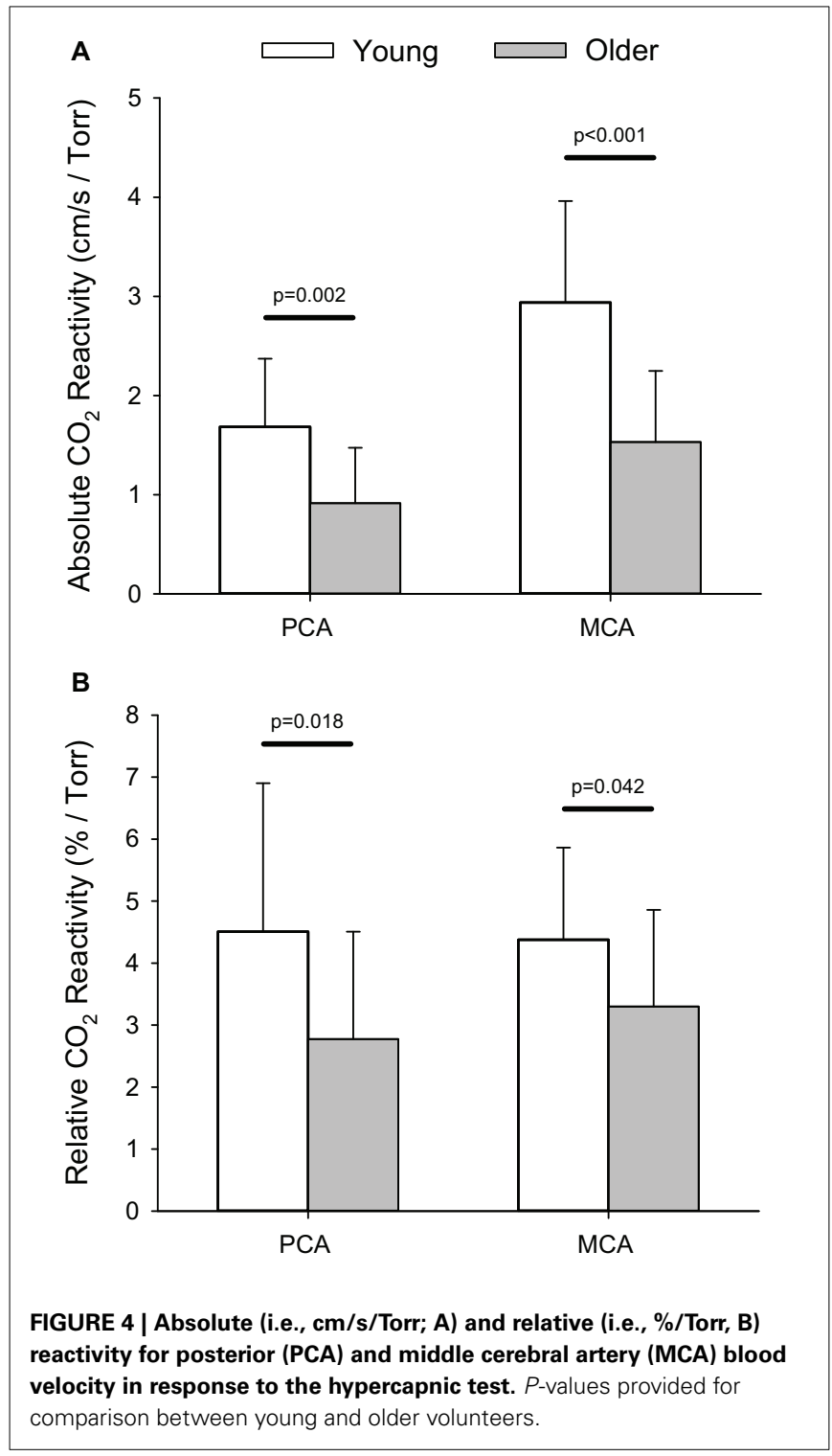

the PCA likely has a reduced capacity to decrease flow (i.e., floor effect) in comparison to the MCA. An additional explanation of why aging may affect the PCA and MCA differently, is that the PCA and MCA bifurcate from different arteries (basilar artery vs. internal carotid artery, respectively) and perfuse differing volumes of brain tissue. The degree of atrophy with healthy aging varies across brain regions with the visual cortex being the most stable across the lifespan (Raz et al., 2005). However, the reduction in $\mathrm{CBF}$ with aging has been reported not to be related to brain atrophy (Chen et al., 2011). Interestingly, cerebral AI values were increased for both the MCA, and PCA, in the older group, but resting $\mathrm{CBF}$ was not related to $\mathrm{AI}$ for either artery (PCA: $R^{2}=0.08, p=0.138$; MCA: $R^{2}=0.04, p=0.290$; data not shown). Therefore, arterial stiffness does not appear to be involved in age-related changes in resting blood flow through these two arteries.

Although visual-evoked increases in blood flow were observed in both the PCA and MCA, the response observed in the PCA
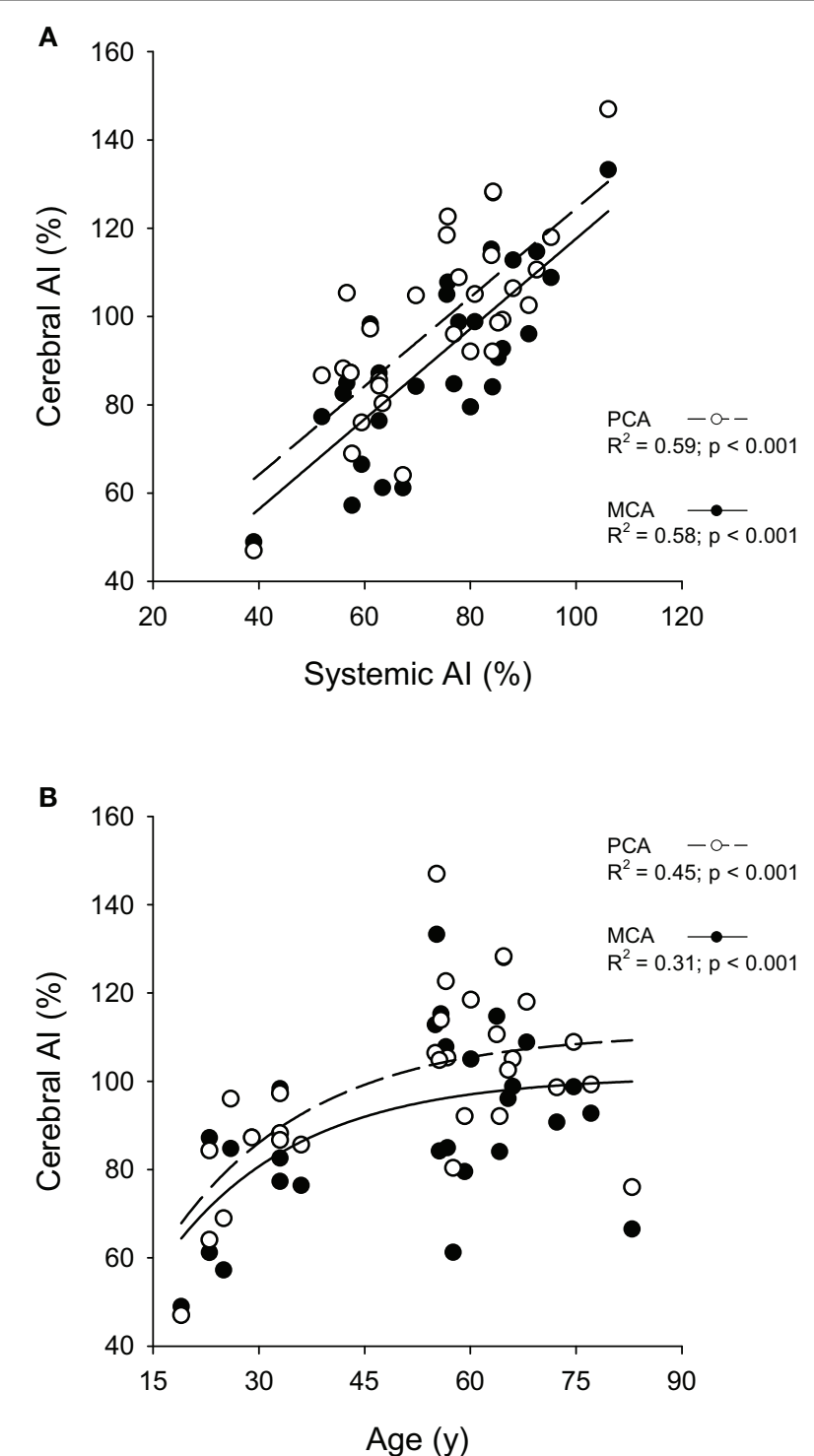

FIGURE 5 | Relationships between the cerebral augmentation index (Cerebral Al) and Systemic Al in the middle (MCA) and posterior cerebral arteries (PCA) (A) and Cerebral Al and Age in MCA and PCA (B).

was much greater in both age groups. In young subjects, PCA blood flow increased $\sim 14 \%$ while blood flow through the MCA increased only $\sim 1 \%$. Similarly, in older subjects, PCA blood flow increased $\sim 8$ vs. a $\sim 3 \%$ increase in MCA blood flow. In contrast, hypercapnia caused similar relative increases in $\mathrm{CBF}$ through both the PCA and MCA ( $18 \%$ in the young group and $~ 14 \%$ in the older group). These contrary responses between the PCA and MCA to these two stimuli reflect the respective local and global responses evoked by the visual stimulation and hypercapnic tests (Tominaga et al., 1976; Aaslid, 1987).

The lower PCA blood flow response to the visual stimulation in the older group is similar to previous studies reporting agingrelated declines in PCA blood flow responses to a visual stimulus 

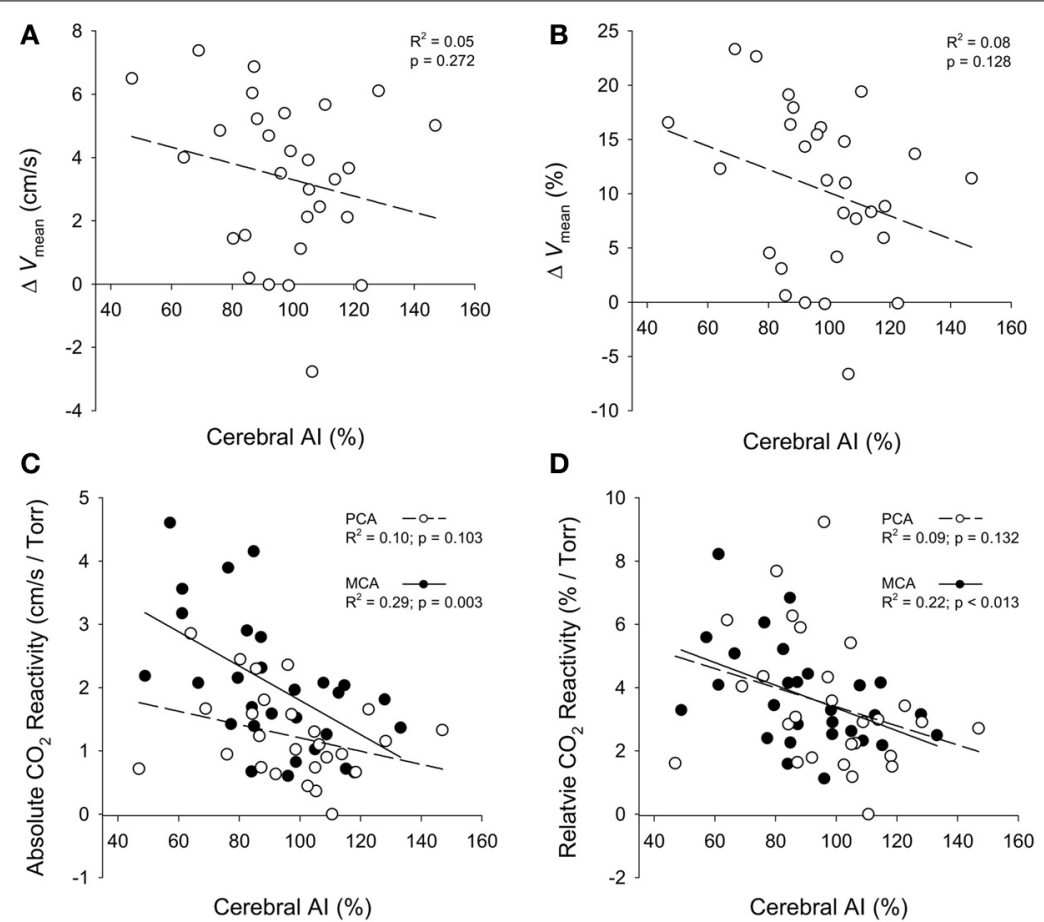

FIGURE 6 | Relationships between the absolute $(\mathrm{cm} / \mathrm{s})$ and relative $(\%)$ changes in PCA mean blood velocity $\left(\Delta V_{\text {mean }}\right)$ in response to the visual stimulation and cerebral $A I(A, B)$; and the

relationships between the absolute $(\mathrm{cm} / \mathrm{s} /$ Torr) and relative (\%/Torr) reactivities to $\mathrm{CO}_{2}$ for the PCA and MCA with cerebral Al (C,D).

(Niehaus et al., 2001; Zheng et al., 2003), but in contrast to other studies reporting no change with increasing age (Panczel et al., 1999; Rosengarten et al., 2003). The mechanism(s) underlying visually evoked blood flow responses is incompletely defined, but include a critical role of the neurovascular unit (i.e., astrocytes in combination with the neurons and blood vessels), as summarized in recent reviews (Iadecola, 2004; Drake and Iadecola, 2007; Iadecola and Nedergaard, 2007; Lok et al., 2007; Koehler et al., 2009). Thus, the observed decrease in PCA blood flow responses with aging may reflect a disruption of the neurovascular unit with aging resulting from neuronal loss and/or vascular remodeling (Panczel et al., 1999).

For cerebrovascular reactivity to hypercapnia, reports are also inconsistent regarding age-related alterations with studies reporting decreased (Nishiyama et al., 1997; Bakker et al., 2004), maintained (Kastrup et al., 1998; Ito et al., 2002; Galvin et al., 2010) and even enhanced hypercapnia reactivity with advancing age (Zhu et al., 2013). The lower PCA and MCA hypercapnic reactivity in the older group observed in the current study are in agreement with the prior studies reporting cerebrovascular reactivity to hypercapnia is decreased with advancing age.

A novel aspect of the current study is the observed decrease in both PCA and MCA reactivity to hypercapnia. Prior studies investigating changes in cerebrovascular reactivity to hypercapnia with aging via TCD have monitored only changes in MCA reactivity (Nishiyama et al., 1997; Kastrup et al., 1998; Ito et al., 2002; Bakker et al., 2004; Galvin et al., 2010; Zhu et al., 2013), thus ignoring potential regional differences that may occur. Therefore, the lower PCA and MCA hypercapnic reactivity in the older group signifies that, in contrast to the regional differences observed in age-related changes in resting CBF, the decreased cerebrovascular reactivity to hypercapnia is a global cerebral phenomenon. The mechanism responsible for the vascular responses to hypercapnia is thought to be the increase in $\mathrm{H}^{+}$concentration in the cerebrospinal fluid which leads to relaxation of the smooth muscle around the cerebral vessels (Gotoh et al., 1961; Kontos et al., 1977a,b; Berne et al., 1981). As a result, the decline in hypercapnic reactivity in both the PCA and MCA reflect a homogenous decline in the capacity of the cerebrovasculature to dilate in response to hypercapnia.

As the mechanisms underlying the regulation of vascular responses to visual stimulation and hypercapnia are different, but both responses are decreased with age, there is a likely common factor that is altered with age contributing to the reduced evoked responses. The mechanical function of the vasculature is involved in both mechanisms and thus, is a likely candidate contributing to the two decreased evoked responses. Furthermore, Zhu et al. (2011) who applied a transfer function method to estimate cerebrovascular impedance, suggested arterial stiffness may contribute to attenuations in CBF with age. With aging, systemic arterial stiffening has been reported to increase in a curvilinear fashion with the greatest increase occurring between 30 and 60 years of age (Kelly et al., 1989; Mitchell et al., 2004; McEniery et al., 2005). Mitchell et al. (2004) reported a leveling off and even a slight decrease of the reflected pressure wave in individuals 50 years of age or older that was explained by an impedance 
matching due to marked increases in aortic stiffness compared to only slight increases in the periphery and, thus a reduction of wave reflection. PCA and MCA cerebral AIs were strongly correlated with systemic AI, and increased reflected waves were observed in both the velocity (i.e., cerebral), and pressure (i.e., systemic) waveforms within both arteries. This high degree of correlation between cerebral and system AI is similar to the studies by Kwater et al. (2009) and Xu et al. (2012) reporting significant correlations between MCA and systemic arterial stiffness indices. Based upon the observed high correlation between cerebral and systemic AI, a curvilinear function was fitted to the cerebral AI and age relationship. Although additional data is needed to fully support a curvilinear relationship between cerebral AI and age due to the gap of $\sim 2$ decades between our young and older groups, the curvilinear relationships plotted had moderate coefficients of determination (i.e., $R^{2}$ ) for the PCA (0.45) and MCA (0.31). Moreover, consistent with the systemic arterial stiffness and age relationship (Kelly et al., 1989; Mitchell et al., 2004; McEniery et al., 2005) the greatest increase in cerebral AI occurred between 20 and 60 years of age. Hence, cerebral and system arterial stiffness may increase in parallel with healthy aging.

Although the negative relationship between the increase in PCA blood flow with visual stimulation and cerebral AI is in agreement with our hypothesis (i.e., increased arterial stiffness contributes to decreased blood flow responses), the relationship was not significant. Similarly, the negative relationship between the PCA hypercapnic reactivity and cerebral AI was not significant. In contrast, a lower MCA hypercapnic reactivity was related to an increased cerebral AI. These divergent findings for the hypercapnic reactivity between the PCA and MCA suggest MCA reactivity is more susceptible to arterial stiffening. The nonsignificant relationship between PCA blood flow responses to the visual and hypercapnic stimuli and cerebral AI may have resulted from the greater variability in the PCA response to hypercapnia and/or the PCA AI having a smaller distribution compared to the MCA AI. Another potential explanation is that AI magnitude is dependent upon wave reflections throughout the vascular bed resulting from vessel branching, changes in vessel wall diameter and/or material properties (Mitchell et al., 2011). Thus, changes in vascular morphology with aging will impact on the relationship between vascular reactivity and cerebral AI. With aging, there is a decrease in the number of downstream blood vessels from the PCA and MCA with a greater decline occurring within the MCA circulation (Bullitt et al., 2010). In contrast, there is a greater increase in vessel tortuosity within the MCA circulation compared to the PCA circulation with advancing age (Bullitt et al., 2010). As a result, the stronger relationship between vascular reactivity through the MCA and cerebral AI may be driven by an increase in vessel tortuosity that occurs with healthy aging.

Lastly, this study has some limitations, which need to be acknowledged. First, TCD measures blood velocity through the insonated artery and not absolute blood flow. However, the two are highly correlated (Brauer et al., 1998). Moreover, the diameter of the PCA during visual stimulation does not change (Aaslid, 1987), and the diameter of both, the PCA, and MCA, has been shown not to change significantly in response to moderate hypercapnia as employed in this study (Giller et al., 1993; Poulin and
Robbins, 1996; Serrador et al., 2000; Willie et al., 2012). Thus, in this situation, changes in blood velocity will lead to a corresponding increase in absolute blood flow. As such, assessment of blood velocity through the PCA and MCA with TCD has been accepted as a reliable index of CBF. Secondly, the gold standard to assess vessel stiffness is pulse wave velocity measurement (Tomlinson, 2012). AI is straightforward to measure, by monitoring blood pressure or blood velocity waveforms; however wave reflections are not only dependent on arterial stiffness but also on the site of reflection. In addition, blood pressure is said to influence the vessel wall properties due to the distending pressure (Chirinos, 2012). However, subjects in the present study were assessed at rest and the chosen time periods used for AI calculations was assured to be as stable as possible.

In conclusion, CBF responses to both visual stimulation and hypercapnia decreased with advancing age with a concomitant increase in cerebrovascular stiffness. The decreases in PCA reactivity to a visual stimulus and hypercapnia were not related to increased cerebrovascular stiffness, whereas MCA hypercapnia reactivity decreased as cerebrovascular stiffness increased. Finally, analysis of the cerebral blood velocity waveform offers a noninvasive approach to assess vascular health and provide an index of arterial stiffness.

\section{AUTHOR CONTRIBUTIONS}

Daniela Flück participated in study design, collected and analyzed TCD data from the older participants, drafted the manuscript, critically reviewed and revised the manuscript; Andrew E. Beaudin and Craig D. Steinback participated in study design, cocollected and co-analyzed TCD data from young participants, critically reviewed and revised the manuscript. Gopukumar Kumarpillai and Nandavar Shobha performed assessments on older participants, critically reviewed and revised the manuscript; Cheryl R. McCreary and Stefano Peca participated in study design, critically reviewed and revised the manuscript; Eric E. Smith conceived of the study, secured study funding, participated in study design, critically reviewed and revised the manuscript; and Marc J. Poulin conceived the study, secured study funding, supervised trainees (Daniela Flück, Andrew E. Beaudin, Craig D. Steinback) and acquisition and analysis of TCD data, critically reviewed and revised the manuscript for intellectual content. All authors approved the final version of the manuscript.

\section{ACKNOWLEDGMENTS}

We thank our dedicated subjects for their participation in this study. This study was supported by operational funds provided by the Canadian Stroke Network (CSN; PI = Eric E. Smith, Co-Applicant = Marc J. Poulin), the Canadian Institutes of Health Research (CIHR; Marc J. Poulin), the Heart and Stroke Foundation of Canada (HSFC; Marc J. Poulin), the Natural Sciences and Engineering Research Council of Canada (NSERC; Marc J. Poulin), the Alzheimer Society of Canada (Eric E. Smith), and the Canadian Foundation for Innovation (CFI; Marc J. Poulin). Andrew E. Beaudin was supported by an AlbertaInnovates-Health Solutions (AI-HS) doctoral fellowship and the CIHR-HSFC Focus on Stroke doctoral fellowship. Craig D. Steinback was supported by NSERC and AI-HS post-doctoral 
fellowships. Eric E. Smith receives salary support from AI-HS and is the Kathy Taylor Chair in Vascular Dementia; and Marc J. Poulin is the Brenda Strafford Foundation Chair in Alzheimer Research.

\section{REFERENCES}

Aaslid, R. (1987). Visually evoked dynamic blood flow response of the human cerebral circulation. Stroke 18, 771-775. doi: 10.1161/01.STR.18.4.771

Ainslie, P. N., Cotter, J. D., George, K. P., Lucas, S., Murrell, C., Shave, R., et al. (2008). Elevation in cerebral blood flow velocity with aerobic fitness throughout healthy human ageing. J. Physiol. 586, 4005-4010. doi: 10.1113/jphysiol.2008.158279

American Psychiatric Association (2000). Diagnostic and Statistical Manual of Mental Disorders (4th Edn., Text Revision). Washington, DC: American Psychiatric Publishing.

Bakker, S. L., De Leeuw, F. E., Den Heijer, T., Koudstaal, P. J., Hofman, A., and Breteler, M. M. (2004). Cerebral haemodynamics in the elderly: the rotterdam study. Neuroepidemiology 23, 178-184. doi: 10.1159/000078503

Beaudin, A. E., Brugniaux, J. V., Vohringer, M., Flewitt, J., Green, J. D., Friedrich, M. G., et al. (2011). Cerebral and myocardial blood flow responses to euoxic hypercapnia and isocapnic hypoxia in humans. Am. J. Physiol. Heart Circ. Phsyiol. 301, H1678-H1686. doi: 10.1152/ajpheart.00281.2011

Benetos, A., Laurent, S., Hoeks, A. P., Boutouyrie, P. H., and Safar, M. E. (1993). Arterial alterations with aging and high blood pressure. A noninvasive study of carotid and femoral arteries. Arterioscler. Thromb. 13, 90-97. doi: 10.1161/01.ATV.13.1.90

Berne, R. M., Winn, H. R., and Rubio, R. (1981). The local regulation of cerebral blood flow. Prog. Cardiovasc. Dis. 24, 243-260. doi: 10.1016/0033-0620(81) 90030-X

Brauer, P., Kochs, E., Werner, C., Bloom, M., Policare, R., Pentheny, S., et al. (1998). Correlation of transcranial Doppler sonography mean flow velocity with cerebral blood flow in patients with intracranial pathology. J. Neurosurg. Anesthesiol. 10, 80-85. doi: 10.1097/00008506-199804000-00003

Bullitt, E., Zeng, D., Mortamet, B., Ghosh, A., Aylward, S. R., Lin, W., et al. (2010). The effects of healthy aging on intracerebral blood vessels visualized by magnetic resonance angiography. Neurobiol. Aging 31, 290-300. doi: 10.1016/j.neurobiolaging.2008.03.022

Chen, J. J., Rosas, H. D., and Salat, D. H. (2011). Age-associated reductions in cerebral blood flow are independent from regional atrophy. Neuroimage 55, 468-478. doi: 10.1016/j.neuroimage.2010.12.032

Chirinos, J. A. (2012). Arterial stiffness: basic concepts and measurement techniques. J. Cardiovasc. Transl. Res. 5, 243-255. doi: 10.1007/s12265-0129359-6

Demirkaya, S., Uluc, K., Bek, S., and Vural, O. (2008). Normal blood flow velocities of basal cerebral arteries decrease with advancing age: a transcranial Doppler sonography study. Tohoku J. Exp. Med. 214, 145-149. doi: 10.1620/tjem. 214.145

Drake, C. T., and Iadecola, C. (2007). The role of neuronal signaling in controlling cerebral blood flow. Brain Lang. 102, 141-152. doi: 10.1016/j.bandl.2006.08.002

Edvinsson, L., and Krause, D. N. (2002). Cerebral Blood Flow and Metabolism. Philadelphia, PA: Lippincott Williams and Wilkins.

Fisher, J. P., Hartwich, D., Seifert, T., Olesen, N. D., McNulty, C. L., Nielsen, H. B., et al. (2013). Cerebral perfusion, oxygenation and metabolism during exercise in young and elderly individuals. J. Physiol. 591, 1859-1870. doi: 10.1113/jphysiol.2012.244905

Folstein, M. F., Folstein, S. E., and McHugh, P. R. (1975). "Mini-mental state." A practical method for grading the cognitive state of patients for the clinician. $J$. Psychiatr. Res. 12, 189-198. doi: 10.1016/0022-3956(75)90026-6

Fonck, E., Feigl, G. G., Fasel, J., Sage, D., Unser, M., Rufenacht, D. A., et al. (2009). Effect of aging on elastin functionality in human cerebral arteries. Stroke 40, 2552-2556. doi: 10.1161/STROKEAHA.108.528091

Galvin, S. D., Celi, L. A., Thomas, K. N., Clendon, T. R., Galvin, I. F., Bunton, R. W., et al. (2010). Effects of age and coronary artery disease on cerebrovascular reactivity to carbon dioxide in humans. Anaesth. Intensive Care 38, 710-717.

Giller, C. A., Bowman, G., Dyer, H., Mootz, L., and Krippner, W. (1993). Cerebral arterial diameters during changes in blood pressure and carbon dioxide during craniotomy. Neurosurgery 32, 737-741. discussion: 741-732.
Gotoh, F., Tazaki, Y., and Meyer, J. S. (1961). Transport of gases through brain and their extravascular vasomotor action. Exp. Neurol. 4, 48-58. doi: 10.1016/00144886(61) $90077-2$

Harris, A. D., Ide, K., Poulin, M. J., and Frayne, R. (2006). Control of endtidal PCO2 reduces middle cerebral artery blood velocity variability: implications for physiological neuroimaging. Neuroimage 29, 1272-1277. doi: 10.1016/j.neuroimage.2005.08.023

Iadecola, C. (2004). Neurovascular regulation in the normal brain and in Alzheimer's disease. Nat. Rev. Neurosci. 5, 347-360. doi: 10.1038/nrn1387

Iadecola, C., and Nedergaard, M. (2007). Glial regulation of the cerebral microvasculature. Nat. Neurosci. 10, 1369-1376. doi: 10.1038/nn2003

Ide, K., Eliasziw, M., and Poulin, M. J. (2003). Relationship between middle cerebral artery blood velocity and end-tidal PCO2 in the hypocapnic-hypercapnic range in humans. J. Appl. Physiol. 95, 129-137. doi: 10.1152/japplphysiol. 01186.2002

Ito, H., Kanno, I., Ibaraki, M., and Hatazawa, J. (2002). Effect of aging on cerebral vascular response to Paco2 changes in humans as measured by positron emission tomography. J. Cereb. Blood Flow Metab. 22, 997-1003. doi: 10.1097/00004647-200208000-00011

Jennings, J. R., Heim, A. F., Kuan, D. C., Gianaros, P. J., Muldoon, M. F., and Manuck, S. B. (2013). Use of total cerebral blood flow as an imaging biomarker of known cardiovascular risks. Stroke 44, 2480-2485. doi: 10.1161/STROKEAHA.113.001716

Kastrup, A., Dichgans, J., Niemeier, M., and Schabet, M. (1998). Changes of cerebrovascular CO2 reactivity during normal aging. Stroke 29, 1311-1314. doi: 10.1161/01.STR.29.7.1311

Kelly, R., Hayward, C., Avolio, A., and O'Rourke, M. (1989). Noninvasive determination of age-related changes in the human arterial pulse. Circulation 80, 1652-1659. doi: 10.1161/01.CIR.80.6.1652

Kety, S. S. (1956). Human cerebral blood flow and oxygen consumption as related to aging. J. Chronic. Dis. 3, 478-486. doi: 10.1016/0021-9681(56)90146-1

Koehler, R. C., Roman, R. J., and Harder, D. R. (2009). Astrocytes and the regulation of cerebral blood flow. Trends Neurosci. 32, 160-169. doi: 10.1016/j.tins.2008.11.005

Kontos, H. A., Raper, A. J., and Patterson, J. L. (1977a). Analysis of vasoactivity of local pH, PCO2 and bicarbonate on pial vessels. Stroke 8, 358-360. doi: 10.1161/01.STR.8.3.358

Kontos, H. A., Wei, E. P., Raper, A. J., and Patterson, J. L. Jr. (1977b). Local mechanism of $\mathrm{CO} 2$ action of cat pial arterioles. Stroke 8, 226-229. doi: 10.1161/01.STR.8.2.226

Kurji, A., Debert, C. T., Whitelaw, W. A., Rawling, J. M., Frayne, R., and Poulin, M. J. (2006). Differences between middle cerebral artery blood velocity waveforms of young and postmenopausal women. Menopause 13, 303-313. doi: 10.1097/01.gme.0000177905.94515.24

Kwater, A., Gasowski, J., Gryglewska, B., Wizner, B., and Grodzicki, T. (2009). Is blood flow in the middle cerebral artery determined by systemic arterial stiffness? Blood Press 18, 130-134. doi: 10.1080/08037050902975114

Laurent, S., Alivon, M., Beaussier, H., and Boutouyrie, P. (2012). Aortic stiffness as a tissue biomarker for predicting future cardiovascular events in asymptomatic hypertensive subjects. Ann. Med. 44(Suppl. 1), S93-S97. doi: 10.3109/07853890.2011.653398

Laurent, S., Cockcroft, J., Van Bortel, L., Boutouyrie, P., Giannattasio, C., Hayoz, D., et al. (2006). Expert consensus document on arterial stiffness: methodological issues and clinical applications. Eur. Heart J. 27, 2588-2605. doi: 10.1093/eurheartj/ehl254

Leenders, K. L., Perani, D., Lammertsma, A. A., Heather, J. D., Buckingham, P., Healy, M. J., et al. (1990). Cerebral blood flow, blood volume and oxygen utilization. Normal values and effect of age. Brain 113(Pt 1), 27-47. doi: 10.1093/brain/113.1.27

Lisak, M., Trkanjec, Z., Mikula, I., and Demarin, V. (2005). Mean blood flow velocities in posterior cerebral arteries during visual stimulation. Mt. Sinai J. Med. $72,346-350$.

Lok, J., Gupta, P., Guo, S., Kim, W. J., Whalen, M. J., van Leyen, K., et al. (2007). Cell-cell signaling in the neurovascular unit. Neurochem. Res. 32, 2032-2045. doi: $10.1007 /$ s1 1064-007-9342-9

McEniery, C. M., Yasmin., Hall, I. R., Qasem, A., Wilkinson, I. B., and Cockcroft, J. R. (2005). Normal vascular aging: differential effects on wave reflection and aortic pulse wave velocity: the Anglo-Cardiff Collaborative Trial (ACCT). J. Am. Coll. Cardiol. 46, 1753-1760. doi: 10.1016/j.jacc.2005.07.037 
Mitchell, G. F., Parise, H., Benjamin, E. J., Larson, M. G., Keyes, M. J., Vita, J. A., et al. (2004). Changes in arterial stiffness and wave reflection with advancing age in healthy men and women: the Framingham Heart Study. Hypertension 43, 1239-1245. doi: 10.1161/01.HYP.0000128420.01881.aa

Mitchell, G. F., van Buchem, M. A., Sigurdsson, S., Gotal, J. D., Jonsdottir, M. K., Kjartansson, Ó., et al. (2011). Arterial stiffness, pressure and flow pulsatility and brain structure and function: the Age, Gene/Environment SusceptibilityReykjavik Study. Brain 134, 3398-3407. doi: 10.1093/brain/awr253

Muller, M., and Schimrigk, K. (1994). A comparative assessment of cerebral haemodynamics in the basilar artery and carotid territory by transcranial Doppler sonography in normal subjects. Ultrasound Med. Biol. 20, 677-687. doi: 10.1016/0301-5629(94)90025-6

Niehaus, L., Lehmann, R., Roricht, S., and Meyer, B. U. (2001). Age-related reduction in visually evoked cerebral blood flow responses. Neurobiol. Aging 22, 35-38. doi: 10.1016/S0197-4580(00)00212-8

Nishiyama, T., Sugai, N., and Hanaoka, K. (1997). Cerebrovascular CO2 reactivity in elderly and younger adult patients during sevoflurane anaesthesia. Can. J. Anaesth. 44, 160-164. doi: 10.1007/BF03013004

Noth, U., Kotajima, F., Deichmann, R., Turner, R., and Corfield, D. R. (2008). Mapping of the cerebral vascular response to hypoxia and hypercapnia using quantitative perfusion MRI at $3 \mathrm{~T}$. NMR Biomed. 21, 464-472. doi: 10.1002/nbm.1210

Panczel, G., Daffertshofer, M., Ries, S., Spiegel, D., and Hennerici, M. (1999). Age and stimulus dependency of visually evoked cerebral blood flow responses. Stroke 30, 619-623. doi: 10.1161/01.STR.30.3.619

Peca, S., McCreary, C. R., Donaldson, E., Kumarpillai, G., Shobha, N., Sanchez, K., et al. (2013). Neurovascular decoupling is associated with severity of cerebral amyloid angiopathy. Neurology 81, 1659-1665. doi: 10.1212/01.wnl.0000435291.49598.54

Poels, M. M., Zaccai, K., Verwoert, G. C., Vernooij, M. W., Hofman, A., van der Lugt, A., et al. (2012). Arterial stiffness and cerebral small vessel disease: the Rotterdam Scan Study. Stroke 43, 2637-2642. doi: 10.1161/STROKEAHA.111.642264

Poulin, M. J., and Robbins, P. A. (1996). Indexes of flow and cross-sectional area of the middle cerebral artery using doppler ultrasound during hypoxia and hypercapnia in humans. Stroke 27, 2244-2250. doi: 10.1161/01.STR.27.12.2244

Raz, N., Lindenberger, U., Rodrigue, K. M., Kennedy, K. M., Head, D., Williamson, A., et al. (2005). Regional brain changes in aging healthy adults: general trends, individual differences and modifiers. Cereb. Cortex 15, 1676-1689. doi: 10.1093/cercor/bhi044

Rey, B., Naranjo, V., Parkhutik, V., Tembl, J., and Alcaniz, M. (2010). A new visually evoked cerebral blood flow response analysis using a low-frequency estimation. Ultrasound Med. Biol. 36, 383-391. doi: 10.1016/j.ultrasmedbio.2009.11.001

Robertson, J. W., Debert, C. T., Frayne, R., and Poulin, M. J. (2008). Variability of middle cerebral artery blood flow with hypercapnia in women. Ultrasound Med. Biol. 34, 730-740. doi: 10.1016/j.ultrasmedbio.2007.07.024

Rosengarten, B., Aldinger, C., Spiller, A., and Kaps, M. (2003). Neurovascular coupling remains unaffected during normal aging. J. Neuroimaging 13, 43-47. doi: $10.1177 / 1051228402239716$

Schwertfeger, N., Neu, P., Schlattmann, P., Lemke, H., Heuser, I., and Bajbouj, M. (2006). Cerebrovascular reactivity over time course in healthy subjects. J. Neurol. Sci. 249, 135-139. doi: 10.1016/j.jns.2006.06.009

Secher, N. H., Seifert, T., and Van Lieshout, J. J. (2008). Cerebral blood flow and metabolism during exercise: implications for fatigue. J. Appl. Physiol. (1985) 104, 306-314. doi: 10.1152/japplphysiol.00853.2007

Serrador, J. M., Picot, P. A., Rutt, B. K., Shoemaker, J. K., and Bondar, R. L. (2000). MRI measures of middle cerebral artery diameter in conscious humans during simulated orthostasis. Stroke 31, 1672-1678. doi: 10.1161/01.STR. 31.7.1672

Smith, E. E., Vijayappa, M., Lima, F., Delgado, P., Wendell, L., Rosand, J., et al. (2008). Impaired visual evoked flow velocity response in cerebral amyloid angiopathy. Neurology 71, 1424-1430. doi: 10.1212/01.wnl.0000327887. 64299.a4
Spelsberg, B., Bohning, A., Kompf, D., and Kessler, C. (1998). Visually induced reactivity in posterior cerebral artery blood flow. J. Neuroophthalmol. 18, 263-267. doi: 10.1097/00041327-199812000-00008

Sturzenegger, M., Newell, D. W., and Aaslid, R. (1996). Visually evoked blood flow response assessed by simultaneous two-channel transcranial Doppler using flow velocity averaging. Stroke 27, 2256-2261. doi: 10.1161/01.STR.27.12.2256

Tominaga, S., Strandgaard, S., Uemura, K., Ito, K., and Kutsuzawa, T. (1976). Cerebrovascular CO2 reactivity in normotensive and hypertensive man. Stroke 7, 507-510. doi: 10.1161/01.STR.7.5.507

Tomlinson, L. A. (2012). Methods for assessing arterial stiffness: technical considerations. Curr. Opin. Nephrol. Hypertens. 21, 655-660. doi: 10.1097/MNH.0b013 e32835856e 3

Vantanajal, J. S., Ashmead, J. C., Anderson, T. J., Hepple, R. T., and Poulin, M. J. (2007). Differential sensitivities of cerebral and brachial blood flow to hypercapnia in humans. J. Appl. Physiol. 102, 87-93. doi: 10.1152/japplphysiol.00772.2006

Wilkinson, I. B., Fuchs, S. A., Jansen, I. M., Spratt, J. C., Murray, G. D., Cockcroft, J. R., et al. (1998). Reproducibility of pulse wave velocity and augmentation index measured by pulse wave analysis. J. Hypertens 16, 2079-2084. doi: 10.1097/00004872-199816121-00033

Willie, C. K., Macleod, D. B., Shaw, A. D., Smith, K. J., Tzeng, Y. C., Eves, N. D., et al. (2012). Regional brain blood flow in man during acute changes in arterial blood gases. J. Physiol. 590, 3261-3275. doi: 10.1113/jphysiol.2012.228551

Xu, T.-Y., Staessen, J. A., Wei, F.-F., Xu, J., Li, F.-H., Fan, W.-X., et al. (2012). Blood flow pattern in the middle cerebral artery in relation to indices of arterial stiffness in the systemic circulation. Am. J. Hypertens 25, 319-324. doi: 10.1038/ajh.2011.223

Yamaguchi, T., Kanno, I., Uemura, K., Shishido, F., Inugami, A., Ogawa, T., et al. (1986). Reduction in regional cerebral metabolic rate of oxygen during human aging. Stroke 17, 1220-1228. doi: 10.1161/01.STR.17.6.1220

Zaletel, M., Strucl, M., Rodi, Z., and Zvan, B. (2004). The relationship between visually evoked cerebral blood flow velocity responses and visual-evoked potentials. Neuroimage 22, 1784-1789. doi: 10.1016/j.neuroimage.2004.04.019

Zheng, X.-N., Zhu, X.-C., Xu, Q.-F., Huang, Y.-N., and Liu, Y. (2003). TCD study of hemodynamic changes in PCA response to photic stimulation. J. Zhejiang Univ. Sci. 4, 228-231. doi: 10.1631/jzus.2003.0228

Zhu, Y. S., Tarumi, T., Tseng, B. Y., Palmer, D. M., Levine, B. D., and Zhang, R. (2013). Cerebral vasomotor reactivity during hypo- and hypercapnia in sedentary elderly and Masters athletes. J. Cereb. Blood Flow Metab. 33, 1190-1196. doi: 10.1038/jcbfm.2013.66

Zhu, Y. S., Tseng, B. Y., Shibata, S., Levine, B. D., and Zhang, R. (2011). Increases in cerebrovascular impedance in older adults. J. Appl. Physiol. (1985) 111, 376-381. doi: 10.1152/japplphysiol.01418.2010

Conflict of Interest Statement: The authors declare that the research was conducted in the absence of any commercial or financial relationships that could be construed as a potential conflict of interest.

Received: 28 November 2013; accepted: 26 January 2014; published online: 19 February 2014.

Citation: Flück D, Beaudin AE, Steinback CD, Kumarpillai G, Shobha N, McCreary CR, Peca S, Smith EE and Poulin MJ (2014) Effects of aging on the association between cerebrovascular responses to visual stimulation, hypercapnia and arterial stiffness. Front. Physiol. 5:49. doi: 10.3389/fphys.2014.00049

This article was submitted to Integrative Physiology, a section of the journal Frontiers in Physiology.

Copyright (C) 2014 Flück, Beaudin, Steinback, Kumarpillai, Shobha, McCreary, Peca, Smith and Poulin. This is an open-access article distributed under the terms of the Creative Commons Attribution License (CC BY). The use, distribution or reproduction in other forums is permitted, provided the original author(s) or licensor are credited and that the original publication in this journal is cited, in accordance with accepted academic practice. No use, distribution or reproduction is permitted which does not comply with these terms. 